\title{
Peer feedback: the learning element of peer assessment
}

Published in Teaching in Higher Education, 11, (3), 279-290.

Ngar-Fun Liu and David Carless

Hong Kong Institute of Education; University of Hong Kong

This paper focuses on peer feedback in relation to assessment processes. It examines the rationale for peer feedback, emphasising its potential for enhanced student learning. We draw on relevant literature to argue that the dominance of peer assessment processes using grades can undermine the potential of peer feedback for improving student learning. The paper throws further light on the issue by drawing on a large-scale questionnaire survey of tertiary students $(1,740)$ and academics (460) in Hong Kong, supplemented by interview data. The findings indicate that a significant number of academics and students resist peer assessment using grades and that the majority report that students never or rarely grade each other in assessment activities. This paper explores why there is resistance, in particular, by academics to peer assessment and argues the case for a peer feedback process as an end in itself or as a precursor to peer assessment involving the awarding of marks. It also recommends some strategies for promoting peer feedback, through engaging students with criteria and for embedding peer involvement within normal course processes.

\section{Introduction}

It is commonly accepted that there are two main purposes of assessment: a certification (or summative) purpose and a learning (or formative) purpose. The first is usually regarded as dominant, with students frequently being reported as driven by a natural desire for high grades (e.g. Becker, Geer \& Hughes, 1995), even when such instrumental motivations may lead to adverse impacts, such as surface learning (e.g. Ramsden, 2003). The authors are currently involved in a project which, whilst acknowledging the dominance of the summative paradigm, seeks to place emphasis on the purpose of assessment related to the promotion of learning. This initiative named the learning-oriented assessment project (LOAP) aims to identify, promote and disseminate good practices at the interface of assessment and learning in higher education in Hong Kong. Our emphasis on 'learning-oriented assessment' (Carless, 2006) indicates that we believe the learning aspects of assessment have considerable potential to be exploited more fruitfully and the project promotes strategies such as peer and self-assessment, which we view as more about learning than about assessment. 
The term assessment is often interpreted as referring to marking, grading, measuring or ranking and as a consequence peer assessment is regarded mainly as students giving marks or grades to each other. However, peer involvement can be more than the teacher sharing with students the responsibility of grading. A reliable assessment depends on knowing what one is trying to assess and by what means one comes to an accurate judgment. Once we begin asking questions about how assessors arrive at marks, we are involved in a process of defining learning outcomes and the criteria for assessing those outcomes. This intellectual engagement with outcomes, criteria and standards is at the heart of student involvement in assessment and can lead to greater clarity about the nature of high quality performance. Engaging learners in thinking about achieving outcomes to certain agreed standards is a learning process and giving marks or grades is only part of that process.

Before proceeding, we indicate how we use the terms peer feedback and peer assessment. By peer feedback we mean a communication process through which learners enter into dialogues related to performance and standards. Peer assessment is defined as students grading the work or performance of their peers using relevant criteria (Falchikov, 2001). So our distinction between the two terms is that peer feedback is primarily about rich detailed comments but without formal grades, whilst peer assessment denotes grading (irrespective of whether comments are also included). Whether grades are awarded or not, the emphasis is on standards and how peer interaction can lead to enhanced understandings and improved learning.

This paper synthesises relevant literature and draws on data from LOAP to make a case for a peer feedback process as an end in itself or as a precursor to peer assessment using grades. We suggest that peer feedback has greater potential for learning than peer assessment, but that some combination of the two may be necessary for pragmatic reasons. Our argument is developed in four stages: firstly, we state the rationale for peer feedback processes; then we suggest that the literature on peer assessment has over-emphasised discussion of the reliability of student grades; thirdly, we draw on LOAP data and outline possible reasons for resistance to peer assessment; finally, the fourth main section suggests some possible ways forward for the implementation of peer feedback. Our discussion is stimulated by the Hong Kong context, but detailed contextual background is not provided as we seek to raise arguments of a general nature 
for consideration across international contexts.

\section{Rationale for peer feedback in assessment processes}

The conceptual rationale for peer assessment and peer feedback is that it enables students to take an active role in the management of their own learning. It is an element of self-regulated learning (Butler \& Winne, 1995) by which students monitor their work using internal and external feedback as catalysts. "Self-regulated learners seek feedback from external sources such as peers' contributions in collaborative groups” (Butler \& Winne, 1995, p. 246). In their model of formative assessment and self-regulated learning, Nicol \& MacFarlane-Dick (2005) also contend that by commenting on the work of peers, students develop objectivity in relation to standards which can then be transferred to their own work.

The link between peer assessment and self-assessment is salient. Peer feedback can enable students to better self-assess themselves as some skills are common to both peer and self-assessment. Boud (1991) defines self-assessment as "the involvement of students in identifying standards and/or criteria to apply to their work and making judgments about the extent to which they have met these criteria and standards” (p.4). Self-assessment can be enhanced by peer contributions which may take the form of questions, comments or challenges which prompt one to reflect on what has been done (Boud, Cohen \& Sampson, 1999). Boud (1995) highlights the interplay of self- and peer assessment as follows, "the defining feature of self-assessment is that the individual learner ultimately makes a judgement about what has been learned, not that others have no input to it" (p.200). Peers provide rich information which can then be used by individuals to make their own self-assessments (Boud, 1995) and follow up with actions to improve their work.

What other reasons are there to engage with peer feedback as a means to promote learning? After all, there are many ways to enhance learning. The answer is a pragmatic one that we suspect many students would find appealing. There is evidence that peer feedback enhances student learning (Falchikov, 2001) as students are actively engaged in articulating evolving understandings of subject matter. Peer feedback thus carries potential for improved performance in high-stakes assessments, something obviously highly valued by students. 
A further practical reason for peer feedback is that students would receive more feedback from peers and more quickly (see Gibbs, 1999, for an example) than when academics are providing comments. With increasing resource constraints and decreasing capacity of academics to provide sufficient feedback, peer feedback can become a central part of the learning process, rather than an occasional option.

A further important reason for engaging learners with peer feedback is that learning is likely to be extended from the private and individual domain, to a more public (i.e. to one or more peers) domain. One important way we learn is through expressing and articulating to others what we know or understand. In this process of self-expression, we construct an evolving understanding of increasing complexity. One aspect of this process is providing learners with opportunities to explore and articulate criteria and standards in the context of working on specific assessment tasks. In order to clarify notions of quality, learners need to analyse real, illustrative exemplars. This is where examining the work of peers offers meaningful opportunities for articulating discipline-specific knowledge, as well as criteria and standards. Once students are at ease with making their work public, we could create conditions under which social learning might be facilitated. This is not to say that making one's work public may not sometimes be threatening, but there are ways to minimise this risk which are discussed in the final section of the paper.

\section{Focus on reliability of peer assessment}

The existing literature on peer assessment has been dominated by studies of peer-tutor grade correlations (Sluijsmans, Brand-Gruwel \& van Merriënbor, 2002). For example, Falchikov \& Goldfinch (2000) carried out a meta-analysis of 48 quantitative peer assessment studies that compared peer and teacher marks, demonstrating that students are generally able to make reasonably reliable judgements. Stefani (1998) in her critique of assessment practices reflects on the dominance of peer grading:

"Many academics became tied to the quantitative analyses of innovative assessment procedures because of the extreme pressure to 'prove' that students could be as reliable as 'assessors' as the tutors ... what some staff seemed to be doing was reducing the concept of student learning and student empowerment, to a series of correlation co-efficients” (p. 343).

Yet, the focus (arguably overemphasis) on reliability of student grading is still prominent as evidenced by further recent examples of measurement-focused forms of peer 
assessment e.g. Miller (2003); Segers \& Dochy, (2001).

Whilst acknowledging that establishing the reliability of student judgements is an important issue, we feel that it is now well-recognised that students are reasonably reliable assessors. We believe (like Stefani) that peer involvement in assessment processes should be more than just grading peers' work and comparing the scores with those of the tutor. The literature also provides some support for a focus on peer feedback rather than peer assessment. Sluijsmans et al., (2001) found that students felt uncomfortable in awarding grades and preferred just giving feedback. Boud, Cohen \& Sampson (1999) reflect as follows, "the use of peer assessment in which students make formal assessments of others within a working group can inhibit cooperation” (p.421). They point out a potential contradiction between a collaborative learning process and individual assessments which often carry a competitive flavour. Boud (2000) argues that, "many forms of peer assessment are ineffective. These are processes in which peers are used as surrogate assessors to generate grades” (p. 157). This generation of grades belongs to the summative rather than the formative purpose of assessment. Brown, Bull \& Pendlebury (1997) argue that resistance by students to informal peer feedback is rare, resistance to formal peer assessment for summative purposes is relatively more frequent, based on three reasons: dislike of judging peers in ways that 'count'; a distrust of the process; and the time involved.

In sum, our belief is that whilst peer assessment involving grading has been much discussed in the literature, in terms of learning, there are more substantive arguments in favour of peer feedback rather than peer assessment. Falchikov, probably the most prominent writer on peer involvement in assessment, seems to reach a similar conclusion as evidenced by the evolvement of her practice towards peer feedback (Falchikov, 1995, 2001, 2005) rather than peer assessment.

\section{Resistance to peer assessment}

This section focuses on data collected from a large-scale questionnaire survey on assessment beliefs and experiences returned by 1,740 tertiary students and 460 academics in Hong Kong (Liu, 2005). This survey is part of LOAP activities referred to in the introduction. Here we use data from just the items most relevant to our discussion to illuminate the issue. It is not our contention that our argument is driven by the data, 
but there are aspects of it that lend support to our position.

One of the questionnaire items sought to find out the frequency of respondents' experience in peer assessment. Academics and students were asked to rate, on a five-point frequency scale, how often "Students graded each other in assessment activities". Table 1 indicates that academics and students reported infrequent use of peer grading: $70 \%$ of academics and $63 \%$ of students reported that students never or rarely grade each other in assessment activities. Another item asked respondents to rate, on a five-point Likert scale, the extent they agree or disagree with possible purposes of assessment. One suggested purpose was “to develop students' ability to assess their classmates”. The evidence in table 2 indicates that the majority of academics did not favour this purpose, whilst students had more receptivity to it than academics, albeit with $65 \%$ still being neutral or in disagreement with that purpose.

\section{TABLES 1 AND 2 ABOUT HERE}

Why do more academics than students think that the assessment process should not be used to develop students' ability to assess each other? More importantly, why do both academics and students appear to have misgivings about students developing the ability to assess classmates? A perspective on these questions can be found in the questionnaire's open-ended data and two subsequent focus group interviews with eight academics from two universities. These sources contained many comments relevant to various issues in assessment and a selection of those most relevant to peer assessment are discussed below. Whilst the claims we can make from these data are modest, we believe they provide a perspective on the issue. As pointed out at the beginning of this paper, the term assessment often denotes grading and the academics interviewed tended to associate peer assessment with grading:

"Perhaps peer assessment is about getting students involved in grading or marking? I know very little about it and have only used it once”.

"I do not use peer assessment, because I think reliability is a problem. Relationships among students may get in the way of fair grading”.

"Peer assessment is only used in group presentations. With individual assessment 
tasks, peer assessment will only increase my workload, because I have to check and collate the marks by students”.

"It is a lot more work to check and collate the marks given by students, especially on project assignments”.

These comments reveal some of the reasons for academics' reluctance to engage in peer assessment using grades. One reason is their concern for reliability. The other is that collating marks is time-consuming. Our interviews with academics also reveal that another reason for resistance is that both Hong Kong academics and students generally considered assessment to be the sole responsibility of the teacher. Academics were viewed as the custodians of standards because they are thought to possess the necessary knowledge and expertise to conduct reliable assessment.

Only one teacher in our focus groups conceives peer assessment as more than grading:

"Peer assessment is about getting and giving feedback, not about giving grades. To overcome the relationship problem, feedback is best given online, rather than in class. Students tend to more forthcoming and constructive online”.

The concept of students' resistance is reflected in the following brief open-ended questionnaire response from a tutor, including a hint that over the longer term, more positive views can be developed:

"Students usually find self and peer assessment a novelty and tend to be uncomfortable with it - at first!”

Overall, the LOAP data indicates that in Hong Kong, students are rarely required to grade each other. There were mixed views of whether developing students' ability to assess their classmates was a suitable purpose of assessment. Interview data revealed concerns from tutors about peer assessment discussed in more detail in the next section.

\section{Possible reasons for resistance to peer assessment}

Our interpretation of data from the LOAP survey and the wider literature indicate four main reasons for resistance to peer assessment processes using grades. These issues of reliability, perceived expertise, power relations and time available are discussed in the subsequent four sub-sections. 


\section{Reliability}

Grading or marking frequently gives rise to discussion of issues of reliability. Academics and students may be reluctant to participate in peer assessment because students, with less knowledge and expertise than academics, are thought even less likely to carry out reliable assessment. In a study at Hong Kong Polytechnic University, Cheng \& Warren (2003) reported their students as having misgivings about awarding grades to peers with some regarding it as "unfair and risky" (p.268) because of doubts about the seriousness and objectivity of their classmates. Of course, reliability is a perennial challenge in Hong Kong and elsewhere. It has led to the pressure to 'prove' that students could be as reliable assessors as academics and stimulated the many studies of peer-tutor grade correlations discussed earlier in the paper.

\section{Perceived expertise}

Earlier in the paper we assert that we cannot reliably assess something, if we do not know what we are trying to assess or by what means we come to a judgment. In this respect, academics are expected to have far more expertise than students. In some contexts, they may even be regarded as possessing the sole expertise for reliable assessment. The issue of perceived expertise is likely to be a major reason for academics and students' resistance to peer grading, and it is perhaps part of the reason why Cheng \& Warren's (op cit) students had some resistance to peer assessment even when they were given training in how to grade. Perceived expertise remains an issue even when grading is not involved, as in the case of peer feedback. Some students may feel that their classmates are not qualified to provide insightful feedback, whilst others may find it easier emotionally to accept feedback from peers. The relationship between perceived expertise and actual expertise remains unclear. Sometimes students may be more perceptive than their classmates give them credit for. There may also be certain kinds of task, such as oral presentations (see Langan et al., 2005 for a discussion), when as a member of the audience students are particularly well-placed to provide feedback.

\section{Power relations}

A third reason for resistance to peer assessment using grades is that it disrupts power relations. Brew (1999) argues that to assess is to have power over a person and sharing the assessment with students, leads to sharing of teacher's power. While academics may 
resist sharing their power (Orsmond, Merry \& Reiling, 2000) students also often dislike having power over peers or peers having power over them (Falchikov, 2001). Isaacs (2001) points out that many students find it uncomfortable to grade friends or fellow students too harshly. For example, students tend to avoid the extreme ends of a scale when marking between groups, whereas they tend to prefer the high end of the scale when grading within their own group. Power relations can lead to the following kinds of peer marking (Brown \& Knight, 1994): “friendship marking”, resulting in over-marking; and "decibel marking", resulting in the noisiest or most dominant getting the highest marks.

Power relations also impact on students because the audience for learners' work is no longer just the teacher, but their peers. Learners may feel resentful because they have to surrender some power and control over their own work. They may also resent the pressure, risk or competition peer assessment could easily engender. These sensitive issues may have been somewhat neglected in the surfeit of studies related to reliability in peer assessment.

\section{Time}

We see the rationale for peer feedback or peer assessment as being its potential for enhanced learning. Some commentators however (e.g. Hanrahan \& Isaacs, 2001) see it in terms of increased efficiencies in the use of staff time. For example, Boud \& Holmes (1995) show how with a large class of electronics students, self- and peer-marking of a mid-term examination both saved staff time and enabled students to receive feedback more promptly. Peer assessment also promotes increased time on task, with students thinking, analyzing, comparing and communicating (Topping, 1998).

In the LOAP survey, both the open-ended comments from the questionnaires and the teacher interview data presented a different picture in that peer assessment was reported as being more time-consuming than traditional assessment. Falchikov (2001) also reports that both academics and students report that peer assessment can be time-consuming. The time factor may act as a discouragement, particularly as peer assessment is generally more complex (Langan et al., 2005) than tutor only marking. Time is also a factor in terms of teaching schedules as when under pressure to cover a certain amount of content within a specific module, many lecturers may perceive peer feedback as an unwanted 
extra.

To sum up this section, we return to the question posed earlier in our discussion of the LOAP data: why do more academics than students think that the assessment process should not be used to develop students' ability to assess each other? If we look at the issues discussed above, it seems that these challenges affect academics more than students. It is the tutor who needs to devote most time to planning and executing peer assessment; and it is the tutor who needs to give up some power. Reliability is an issue for both students and academics, yet it is the teacher whose job it is to ensure that assessments are reliable. Only the issue of perceived expertise is more of a concern to students rather than staff.

\section{Possible ways forward}

Building on the rationale for peer feedback at the outset of the paper, we now propose three possible ways forward: peer feedback integrated with peer assessment; strategies for engaging students with criteria; and cultivating a course climate for peer feedback.

\section{Peer feedback integrated with grading}

One way of tackling the challenges in peer assessment, such as reliability, power relations and time is if peers are not involved in grading. If students are not required to award marks to each other, the reliability of their grading will not be an issue. Neither would academics need to spend time on collating and checking the marks. This could indicate that peer feedback might be preferable to peer assessment and for some well-motivated students this may well be the case. But to advocate the abandonment of peer grading altogether is to ignore the centrality of marks to the whole student experience of assessment. In their study of peer review, Pond, Ul-Haq \& Wade (1995) found that one of the problems was low student motivation for the process, when peer feedback had no bearing on summative assessment. As Brown, Bull \& Pendlebury (1997) point out, in order to encourage students to accept peer feedback, it may need to be incorporated within systems of summative assessment. There are strategies by which this could be implemented flexibly. For example, the peer portion of the assessment could carry a modest weighting (Race, 1998); peer assessment could involve multiple peers to minimise risks of bias; or perhaps not all peer generated marks would need to be counted for summative assessment; or as a further variation, students might take more control of 
the process by choosing their best pieces of peer-assessed work as part of a learning portfolio.

A useful way of motivating students to carry out peer feedback rigorously is described by Bloxham \& West (2004). They awarded 25\% of their assignment marks for the quality of peer marking in order to encourage their students to carry it out seriously. This was an extra incentive for students to think carefully about the assessment criteria and the writing of feedback. Many of the students involved were reported as recognising the benefits of peer marking for their own development as learners and the authors suggest that awarding marks for the peer feedback element added to the motivation of students and the amount they gained from the exercise.

\section{Strategies for engaging students with criteria and quality}

As indicated earlier, one of the advantages of peer involvement in assessment is that it engages students more actively with the identification of standards and the criteria representing these standards. This in turn can help them to develop conceptions of quality approaching that of their lecturers and so be in a better position to process tutor feedback. Extending this point further, all actions which help to increase the transparency of assessment to students are likely to be beneficial. Understanding criteria and the academic discourse in which they may be embedded is challenging and may require training (Hanrahan \& Isaacs, 2001), but this kind of understanding is fundamental to collaborative forms of assessment.

The literature discusses a variety of strategies to support student engagement with standards. One strategy is student development of assessment criteria as arguably students may be better able to make sound judgements if they have been involved in the generation of the criteria. For example, Orsmond, Merry \& Reiling (2002) discuss how student generation of criteria, lecturer feedback on the criteria and the use of exemplars helped students to become better aware of the standards required. An interesting finding was that when asked to assess a product, a peer assessor was able to make a more objective judgement than the self-assessor. This reinforces the important point made earlier that peer feedback can support the development of the self-assessment skills so essential to lifelong learning. 
Sadler (2002) argues that high standard exemplars (typically previous student assignments) are more effective than a focus on criteria. He distinguishes between qualities (as represented in criteria) and high quality work as follows:

"Listing criteria separately invites students to think about qualities rather than quality ... Quality is determined by how the specified - and the unspecified criteria are invoked in practice, and how all the various qualities contribute together in concert” (p. 135).

Sadler goes on to point out how experiencing quality through viewing outstanding assignments had a potent impact on his students.

\section{Cultivating a course climate for peer feedback}

A further strategy for facilitating effective peer involvement in assessment is through embedding it within regular course processes. Boud (2000) recommends the creation of a course climate in which the giving and receiving of peer feedback is a normal part of teaching and learning processes. The more involvement in peer feedback processes, the more likely students are to develop the necessary expertise for sound judgements.

Orsmond, Merry \& Reiling (2000) argue that peer involvement in assessment, conducted in a non-threatening, collaborative atmosphere, enables students to learn better because it prompts them to think more critically. They also suggest that students' initial difficulties or reluctance can be overcome with time, experience and support.

As suggested earlier, part of the process of peer feedback involves making student work public in which social learning can take place. Because of the potential risks for students (loss of privacy or face, embarrassment or even humiliation), making their work public can most fruitfully be carried out when the rationale for it has been discussed and accepted; positive and trusting peer relations exist; and a collaborative learning climate has been established. A further point to consider is that some assessment tasks are more amenable to the peer feedback process than others, so peer feedback might be part of a suite of techniques in promoting student involvement in assessment. Cultivating an appropriate atmosphere for peer interaction is clearly a necessary condition for successful peer feedback processes. 


\section{Conclusion}

This paper has argued that the literature on peer assessment has over-emphasised comparison of tutor-student grades, thereby underplaying other features of peer learning processes. We have made the case for peer feedback as an end in itself, as well as a precursor to peer assessment involving the awarding of marks. Our argument falls within a wider agenda (e.g. Gibbs \& Simpson, 2004) of arguing for assessment which supports learning and measurement, rather than stressing measurement to the detriment of learning.

We have put arguments for peer feedback processes to develop skills such as critical reflection, listening to and acting on feedback, sensitively assessing and providing feedback on the work of others. Students can learn not only from the peer feedback itself, but through meta-processes such as reflecting on and justifying what they have done. However, do academics subscribe to the viewpoint that they have a major responsibility in developing these lifelong learning skills? This is a key tension. If teaching and learning cultures emphasise individual achievement to the detriment of more collaborative approaches, the potential of peer feedback for learning may not be fully realised.

\section{Acknowledgements}

We would like to thank all colleagues involved in LOAP activities and David Boud for his inspiration and support.

\section{References}

Becker, H., Geer, B., \& Hughes, E. (1995) Making the grade: the academic side of college life (2nd edn) (New Brunswick, NJ, Transaction publishers).

Bloxham, S. \& West, A. (2004) Understanding the rules of the game: marking peer assessment as a medium for developing students' conceptions of assessment. Assessment and Evaluation in Higher Education, 29(6), 721-733.

Boud, D. (1991) HERDSA Green Guide, no.5: Implementing student self-assessment (2nd edn) (Sydney, Higher Education Research and Development Society of 
Australasia).

Boud, D. (1995) Enhancing Learning through Self Assessment (London, Kogan Page).

Boud, D. (2000) Sustainable assessment: rethinking assessment for the learning society. Studies in Continuing Education, 22(2), 151-167.

Boud, D. Cohen, R \& Sampson J. (1999) Peer learning and assessment. Assessment and Evaluation in Higher Education, 24(4), 413-426.

Boud, D. \& Holmes, H. (1995) Self and peer marking in a large technical subject, in: D. Boud, Enhancing Learning through Self Assessment (London, Kogan Page).

Brew, A. (1999) Towards autonomous assessment: using self-assessment and peer assessment, in: S. Brown \& A. Glasner (Eds) Assessment matters in higher education (Buckingham, England, Society for Research into Higher Education \& Open University Press).

Brown, G., Bull, J. \& Pendlebury, M. (1997) Assessing student learning in higher education (London \& New York, Routledge).

Brown, S. \& Knight, P. (1994) Assessing learners in higher education (London, Kogan Page).

Carless, D. (2006) Learning-oriented assessment: conceptual basis and practical implications. Innovations in Education and Teaching International.

Cheng, W. \& Warren, M. (2003) Having second thoughts: student perceptions before and after a peer assessment exercise, in: P.Stimpson, P.Morris, Y.Fung \& R.Carr (Eds) Curriculum, learning and assessment: the Hong Kong experience (Hong Kong, Open University of Hong Kong Press).

Falchikov, N. (1995) Peer feedback marking: developing peer assessment. Innovations in Education and Training International, 32(2), 175-187.

Falchikov, N. (2001) Learning together: peer tutoring in higher education (London, Routledge Falmer).

Falchikov, N. (2005) Improving assessment through student involvement (London, 
Routledge Falmer).

Falchikov, N. \& Goldfinch, J. (2000) Student peer assessment in higher education: a meta-analysis comparing peer and teacher marks. Review of Educational Research, 70 (3), 287-322.

Gibbs, G. (1999) Using assessment strategically to change the way students learn, in: S. Brown \& A. Glasner, (Eds) Assessment Matters in Higher Education (Maidenhead, SRHE and Open University Press).

Gibbs, G, \& Simpson, C. (2004) Conditions under which assessment supports students’ learning. Learning and Teaching in Higher Education, 1, 3-31.

Hanrahan, S. \& Isaacs, G. (2001) Assessing self- and peer-assessment: the students' views, Higher Education Research and Development, 20(1), 53-70.

Isaacs, G. (2001) Assessment for learning. (Brisbane, The University of Queensland).

Langan, M. and 10 associates (2005) Peer assessment of oral presentations: effects of student gender, university affiliation and participation in the development of assessment criteria. Assessment and Evaluation in Higher Education, 30(1), 21-34.

Liu, N. F. (2005) Hong Kong academics' and students' perceptions of assessment purposes and practices. (Learning Oriented Assessment Project report, Hong Kong Institute of Education).

Miller, P., J. (2003) The effect of scoring criteria specificity on peer and self-assessment. Assessment and Evaluation in Higher Education, 28(4), 383-394.

Nicol, D. \& MacFarlane-Dick, D. (2005) Formative assessment and self-regulated learning: A model and seven principles of good feedback practice. Studies in Higher Education.

Orsmond, P. Merry, S. \& Reiling, K. (2000) The use of students derived marking criteria in peer and self-assessment, Assessment and Evaluation in Higher Education, 25 (1), 23-28 
Orsmond, P., Merry, S. \& Reiling, K. (2002) The use of exemplars and formative feedback when using student derived marking criteria in peer and self-assessment, Assessment and Evaluation in Higher Education, 27(4), 309-323.

Pond, K., Ul-Haq, R. \& Wade, W. (1995) Peer review: a precursor to peer assessment, Innovations in Education and Training International, 32(4), 314-323.

Race, P. (1998) Practical pointers on peer assessment, in: S.Brown (Ed) Peer assessment in practice (Birmingham, SEDA publications).

Ramsden, P. (2003) Learning to teaching in higher education (2nd edn) (London, Routledge).

Sadler, R. (2002) Ah! ... So that’s ‘quality’, in: P. Schwartz \& G. Webb (Eds) Assessment: case studies, experience and practice from higher education (London, Kogan Page).

Segers, M., \& Dochy, F. (2001) New assessment forms in problem-based learning: the value added of the students' perspective, Studies in Higher Education, 26(3), 327-343.

Sluijsmans, D., Brand-Gruwel, S. \& Van Merriënbor, J. (2002) Peer assessment training in teacher education: effects on performance and perceptions. Assessment and Evaluation in Higher Education, 27(5), 443-454.

Sluijsmans, D., Moerkerke, G., Van Merriënbor, J. \& Dochy, F. (2001) Peer assessment in problem-based learning, Studies in Educational Evaluation, 27, 153-173.

Stefani, L. (1998) Assessment in partnership with learners. Assessment and Evaluation in Higher Education, 23(4), 339-350.

Topping, K. (1998) Peer assessment between students in colleges and universities. Review of educational research, 68(3), 249-276. 
Table 1. Summary of responses to "Students graded each other in assessment activities"

\begin{tabular}{lcc}
\hline & Academics & Students \\
\hline Never or rarely & $70 \%$ & $63.2 \%$ \\
Sometimes & $22.6 \%$ & $28.5 \%$ \\
Often or always & $7.4 \%$ & $8.3 \%$ \\
\hline
\end{tabular}

Table 2. Summary of responses to the assessment purpose of “developing students' ability to assess their classmates"

Academics Students

\begin{tabular}{lll}
\hline Agree or strongly agree & $23 \%$ & $35 \%$ \\
Neutral & $36 \%$ & $40 \%$ \\
Disagree or strongly disagree & $41 \%$ & $25 \%$ \\
\hline
\end{tabular}

